\title{
Effects of Visual Communication on Memory Enhancement of Thai Undergraduate Students, Kasetsart University
}

\author{
Patchara Vanichvasin ${ }^{1}$ \\ ${ }^{1}$ Faculty of Education, Kasetsart University, Bangkok, Thailand \\ Correspondence: Patchara Vanichvasin, Faculty of Education, Kasetsart University, Bangkok, Thailand. E-mail: \\ feduprv@ku.ac.th
}

Received: October 16, 2020

Accepted: November 21, $2020 \quad$ Online Published: December 5, 2020

doi:10.5539/hes.v11n1p34

URL: https://doi.org/10.5539/hes.v11n1p34

\begin{abstract}
Memory is important in a learning process. The more students can memorize or retain information from a learning process, the greater possibility students can perform better in their learning. Therefore, this research aimed to explore visual communication in terms of its effectiveness and effects on memory enhancement with 19 Thai undergraduate students by using a communication skills online course with visual communication, an evaluation questionnaire of the selected course, an effectiveness questionnaire of visual communication, and a memory test on the selected course. Mean, standard deviation, content analysis and a t-test for dependent samples were used to analyze data collected from all research instruments. The research findings indicated that using visual communication produced positive results in enhancing student memory and thus generating greater student learning, which can be concluded that visual communication has high potential to be implemented in class as an effective tool for teaching courses to enhance student memory and thus create better learning performance.
\end{abstract}

Keywords: effects, visual communication, memory enhancement

\section{Introduction}

Memory is important for success in a learning process because learning is related to the acquisition of information and subsequent retention of the acquired information is called memory (Avneet, Pal Singh, \& Siddhraj, 2018). It is therefore acquired information stored or left from a learning process, which is to be transformed into knowledge and knowledge is to be translated into skills to be successful in learning (Van De Ven \& Johnson. 2006). The more students can memorize or retain acquired information from a learning process, the greater possibility students can perform better in their learning.

Researches in education suggest that using visuals in teaching results in better learning (Stokes, 2002) because pictures have more advantages than words (Dewan, 2015). People learn and retain information presented to them visually much better than information provided verbally (Hewlett-Packard Development Company, 2004). Courses deliver information with visual form increase memory recall better than courses delivering with textual form due to the fact that visuals enable people to interpret the content and direct attention, which helps increase the possibilities that the learners will remember (Gutierrez, 2014) while retention of information increases dramatically when using visuals (Nelson, Reed, \& Walling, 1976). As a result, visual cues help us better retrieve and remember information (Kouyoumdjian, 2012). Also, learners demonstrate higher interest in the message when they are given visuals rather than when they are presented with texts (Khadimally, 2016). Communicating visually can strongly improve comprehension and retention (Digital Splash Media, 2014). Thus, effective communication supported with visuals adding to the textual information can generate significantly positive learning outcomes, especially the learners who find the content engaging and authentic (Reiser \& Dempsey, 2007) as learning is facilitated when the visuals and texts work together to communicate the instructional messages (Clark \& Mayer, 2011).

At present, Thailand is facing challenges with the tradition of passive learning (Sanitchai \& Darrin, 2018) as it tends to focus heavily on content (Mala, 2017). Subjects were taught using the conventional lecture approach, implying passive learning by the students (Movien, 2015). Teachers take control of their classes and use lectures as the basis of their teaching approach (Saengboon, 2002) while students take on a passive role (Saengboon, 2006) and are forced to memorize content instead of truly understanding and learning the content (Thamraksa, 
2003). However, teaching with a content-based approach does not support memorization. According to Sharma, Bhosle, \& Chaudhary (2012), 75\% of all information processed in human brain is from visual communication because the human brain processes images 60,000 times faster than texts, and 90 percent of information transmitted to the brain is visuals (Eisenberg, 2014), which facilitates better memorization of content.

Visual communication is considered as an effective teaching approach to convert a content-based or text-based course into a visual-based one in order to make memorization easier and generate better learning performance. It is the communication of information through the visual display of information (Alfi, 2011), which is achieved by communicating an instructional message and displaying it in a format that enables people to clearly see an instructional message and easily understand what they see (Few, 2006) with three basic provisions of appeal to draw attention and engage an audience, comprehension to generate a clear understanding, and retention to remember and recall the information presented by visual communication (Lankow, Ritchie \& Crooks, 2012; Wulandari, 2018). However, numerous researches in Thailand have been focused on infographics, which were one form of visual communication (see, for example, Jantanamsri, 2017; Vanichvasin, 2013; Rasi, 2016) while not many researches have been conducted in visual communication as a whole.

The researcher is therefore interested in studying the use of visual communication with various forms of visuals to investigate its effectiveness and effects on memory enhancement of students. It was expected that the research results would be guidelines for establishing visual communication as a useful teaching tool for better memorization of content, which can lead to better learning performance.

\section{Literature Review}

Visual communication is the conveyance and delivery of information to the viewers through the use of visual elements that can be read, looked upon (Alfi, 2011; Basker, 2009; Freeman, 2019) and get connected to information (Smiciklas, 2012). It relies on eye sight and on a brain that transmits, processes, interprets all the sensory information received (Sless, 1981; Lester, 2012; Eisenberg, 2014). It can include signs, typography, drawing, graphic design, infographics, illustration, industrial design, advertising, animation, color, diagrams, sketches, charts, photographs, video, objects, models, maps, slide presentation, animation and electronic resources (Alfi, 2011; Smith, 2005; Wilmot Li \& Berthouzoz, 2011).

The fundamental goal of visual communication is to produce the best possible picture at the lowest data rate (Huck, Fales \& Rahman, 1997) because visual communication communicates and displays information in a format that enables people to clearly see information and understand what they see (Few, 2006). In fact, the human brain processes images 60,000 times faster than text, and 90 percent of information transmitted to the brain is visuals (Eisenberg, 2014) while 75\% of all information processed in human brain is from visual communication (Sharma, Bhosle, \& Chaudhary, 2012). Therefore, when visual elements are incorporated into text-based content, communication gets more effective. In theory, effective visual communication should consist of three basic provisions, which are 1) appeal to draw attention and engage an audience, 2) comprehension to generate a clear understanding, and 3) retention to remember and recall the information presented by visual communication (Lankow, Ritchie \& Crooks, 2012; Wulandari, 2018). Numerous studies indicated that attention can increase memory performance in terms of the recall rates (Smilek et al., 2002; Pan, 2012). In addition, the human brain quickly recognizes, stores and recalls images, seamlessly and subconsciously cementing ideas in long-term memory (Wulandari, 2018) because images contain two codes, that is, one visual and the other one verbal. Each is stored in different places in the brain (Paivio, 1986). The dual-coding natures of images allows for two independent ways of accessing visual memories, increasing the odds of remembering at least one of them due to the fact that visual and verbal memories are stored separately and the best recall happens when one can access one or the other while words only enter the long-term memory with a single code (Kosslyn, 2007).

There are many benefits of visual communication. According to Freeman (2019), visual communication can communicate information faster and better through its visual elements because it helps process visual information with less language barriers as compared to a paragraph of text, stimulates interest from viewers with their visual elements, generates easy to understanding information, and provides the ease of remembering and retaining the information (Choudhary, 2019; Dimension Data, 2013; Lankow, Ritchie \& Crooks, 2012; Alfi, 2011). Also, there is various evidence from current research studies indicating that communication that has a visual component can be far more effective than communication that does not ((Hewlett- Packard Development Company, 2004).

In educational settings, learning success is the teacher's ability to communicate effectively with students in a learning process. Without good communication, teachers can make the learning process of students ineffective. When a teacher communicates ineffectively with students, their comprehension drops, and they eventually lose 
grasp of the subject matter (Mayhew, 2017). As a result, communication is important to successful teaching and learning. Therefore, visual communication can play an important role to support the teaching and learning process in a way that graphics and texts work together to communicate the instructional messages (Clark \& Mayer, 2011). Due to its benefits, teachers can use visual communication to convey and deliver course content in order to generate interest, comprehension and retention through the variety of visual elements. Furthermore, adding visual elements to words can be a powerful way to help learners engage in active learning (Mayer, 2003) while offering positive learning outcomes on the part of the learners who find the content engaging and authentic (Reiser \& Dempsey, 2007).

The study of visual communication can have important impact to education as it is explicit that visual communication has high potential for use in teaching and learning process. With visual communication, course content is communicated in a format that is easy to understand, stimulates interest and helps retain the content. As a result, memory of students can be enhanced and their learning performance can be increased.

\section{Method}

To evaluate the effectiveness of visual communication and examine its effects on memory enhancement of students, a quasi-experimental research design was implemented by developing the communication skills online course with visual communication from documentary review on theories and related researches in visual communication. The developed online course was then examined by 3 experts with an evaluation questionnaire and pilot tested by a group of 10 non-targeted samples, who studied the same course with an effectiveness questionnaire. After revising the course from expert comments and feedback of non-targeted samples on the use of visual communication, the researcher then used it for teaching over a period of 15 sessions with 19 targeted samples, who enrolled in the selected course. The researcher evaluated the effectiveness of visual communication with a questionnaire and examined the effects of visual communication on memory enhancement of students through their learning performance with pre-test and post-test results.

\subsection{Participants}

The researcher used the purposive sampling method to select only participants, who registered for the selected course implementing visual communication at Kasetsart University. Therefore, 19 Thai undergraduate students were selected to be participants in the study.

\subsection{Instruments}

The communication skills online course with visual communication was designed and developed to explore the effectiveness of visual communication and its effects on memory enhancement of students with three research instruments, that is, an evaluation questionnaire, an effectiveness questionnaire and a memory test. The details were as following.

The communication skills online course with visual communication was designed and developed from the literature review of visual communication and content of a regular communication skills course. 3 experts evaluated it with an evaluation questionnaire and the pilot test was done with a group of 10 non-target samples, who studied the same course.

An evaluation questionnaire based on three basic provisions of effective visual communication was utilized to obtain opinions from experts. It consisted of 9 items on a 5 Likert scale basis (1=very low to $5=$ very high) in three basic provisions, that is, appeal, comprehension and retention with an open-ended question at the end of the questionnaire. The results of scores and recommendations were reported and utilized to improve the course before its use.

An effectiveness questionnaire was utilized to obtain students' perceived effectiveness of the visual communication including feedback and comments. It was developed from the literature review of visual communication. It consisted of 20 items on a 5 Likert scale basis ( $1=$ very low to $5=$ very high) in three functions, that is, communicating content, enhancing memory, and increasing learning with an open-ended question at the end of the questionnaire for further recommendation. The index of item-objective congruence (IOC) ranged from 0.67-1.00 according to expert opinions while the values of reliability coefficient were established at 0.94 according to the pilot study with 10 non-target group of samples.

A memory test was developed from the course content using a pretest-posttest design to investigate the effects of visual communication on memory enhancement of students before and after the implementation of visual communication. The memory test consisted of 20 multiple choice questions, each with 4 possible answers but only one correct answer to investigate the understanding of the course content. Each correct answer was worth one score. The total scores ranged from 0 to 20 indicating the memory of the course content. The validity was 
verified by 3 experts with the index of item-objective congruence (IOC) ranging from $0.67-1.00$. The pilot study was done with 10 non-target group of samples with the values of reliability coefficient at 0.83 . The difficulty (P) and discrimination values (r) were analyzed and reported between $0.20-0.80$ and $0.20-1.00$, respectively.

\subsection{Data Collection}

The target group of students took the pre-test in the first session before the use of visual communication. After completing the pre-test, they studied the developed communication skills online course over a period of 15 sessions. At the end of semester, the post-test was distributed to investigate the visual communication's effects on memory enhancement of students and the effectiveness questionnaire to obtain student perceptions towards the effectiveness of visual communication including feedback and comments. Finally, the completeness and accuracy of all instruments were checked before proceeding to data analysis.

\subsection{Data Analysis}

Data obtained from an evaluation questionnaire, an effectiveness questionnaire, a memory test were analyzed. Quantitative data from opinions of experts and non-targeted group of samples on the applicability and the effectiveness of visual communication were used. A 5 Likert scale basis (from very low (1) to very high (5) scale) was utilized to evaluate the applicability of visual communication according to expert opinions and the perceived effectiveness of visual communication from student opinions. The t-test for dependent samples was used to determine if there was a significant difference between the means of students' memory before and after the use of visual communication or not. Qualitative data from open ended questions was reported to summarize recommendations from experts and feedback on visual communication from students. Statistics used for data analysis were mean, standard deviation, content analysis, and a t-test for dependent samples with the p-value set at statistical significance of .05 level.

\section{Results and Discussion}

The research findings were as follows

\subsection{The Developed Communication Skills Online Course with Visual Communication}

The communication skills online course with visual communication was developed from a regular communication skills course to add visual forms of visual communication such as animation, graphics, colors, videos, and typography in order to turn the existing content-based or text-based course to the visual-based one according to the literature review of visual communication. There were 11 videos created by the researcher for students studying online over a period of 15 sessions. Before using, they were reviewed by 3 experts in the field of education as appropriate $(\overline{\mathrm{X}}=4.56$, S.D. $=0.40)$ for use at very high level in its appeal, retention and comprehension, which were three basic provisions of effective visual communication.

Table 1. Mean and Standard Deviation of the Applicability of Visual Communication

\begin{tabular}{lccl}
\hline Applicability of Visual Communication & $\overline{\mathrm{x}}$ & S.D. & Interpretation \\
\hline Appeal & & & \\
1. The content is stimulating & 4.67 & 0.58 & Very high \\
2. The content is attractive & 5.00 & 0.00 & Very High \\
3. The content is engaging & 4.33 & 0.58 & High \\
Comprehension & & & \\
4. Understanding the content quickly with minimal effort & 4.67 & 0.58 & Very High \\
5. Understanding the content clearly & 4.33 & 0.58 & High \\
6. Understanding the knowledge of the course content & 4.33 & 0.58 & High \\
Retention & & & \\
7. Highlight on essentials of the content & 4.67 & 0.58 & Very high \\
8. Rapid connection to the content & 4.33 & 0.58 & High \\
9. Right balance of the content, which is easy to recall & 4.67 & 0.58 & Very High \\
Total & 4.56 & 0.40 & Very high \\
\hline
\end{tabular}

From table 1, it demonstrated that mean and standard deviation (S.D.) of the applicability of visual communication were 4.56 and 0.40 , respectively. This meant that the developed communication skills online course with visual communication was appropriate for use with targeted students at very high level. It was then pilot tested with a group of 10 non-targeted samples with the perceived effectiveness at high level. After revising the course from comments of experts and feedback of non-targeted samples on the use of visual communication, 
it was ready for use in the next step of this research.

\subsection{The Effectiveness of Visual Communication according to Student Perceptions}

The developed communication skills online course with visual communication was used to teach students online in 15 sessions. The researcher had dual roles of a researcher and an instructor to introduce visual communication at the first session, clarify the research purposes, and invite students to be participants in the research study. There were 11 videos related to the content taught in each session. All students attended the online class using visual communication. In the last session, an effectiveness questionnaire was distributed to students to measure the effectiveness of visual communication according to student perceptions. The perceived effectiveness of visual communication was demonstrated in Table 2.

Table 2. Mean and Standard Deviation of Students' Perceived Effectiveness

\begin{tabular}{lccc}
\hline Students' Perceived Effectiveness of Visual Communication & $\overline{\mathrm{X}}$ & S.D. & Interpretation \\
\hline Communicating Content with Visual Communication & & & \\
1. Visual content is clear and concise & 4.58 & 0.51 & Very High \\
2. Amount of texts is appropriate & 4.53 & 0.51 & Very High \\
3. Videos are well presented & 4.63 & 0.50 & Very High \\
4. Animation used is appropriate & 4.47 & 0.61 & High \\
5. Graphics used are appropriate & 4.47 & 0.70 & High \\
6. Colors used are appropriate & 4.32 & 0.67 & High \\
7. Typography used is appropriate & 4.00 & 0.82 & High \\
8. Easiness to understand content communicated & 4.74 & 0.56 & Very High \\
Enhancing Memory with Visual Communication & & & \\
9. Content summary used helps memory enhancement & 4.84 & 0.37 & Very High \\
10. Easiness to recall, remember, recap, and retrieve course content & 4.84 & 0.37 & Very High \\
11. Mind map used helps memory enhancement & 4.47 & 0.70 & High \\
12. Graphics used help memory enhancement & 4.47 & 0.61 & High \\
13. Animations used help memory enhancement & 4.53 & 0.77 & Very High \\
14. Colors used help memory enhancement & 4.32 & 0.67 & High \\
15. Typography used helps memory enhancement & 4.16 & 0.76 & High \\
Increasing Learning with Visual Communication & & & \\
16. Visual communication motivates student to study & 4.79 & 0.42 & Very High \\
17. Visual communication appeals to students' interest & 4.63 & 0.50 & Very High \\
18. Visual communication enhances memory, thus leads to learning & 4.63 & 0.50 & Very High \\
19. Visual communication used satisfies students & 4.74 & 0.45 & Very High \\
20. Visual communication used helps study better & 4.68 & 0.48 & Very High \\
Total & 4.27 & 0.38 & High \\
\hline
\end{tabular}

Table 2 illustrated that students perceived the effectiveness of visual communication at high level $(\bar{x}=4.27$, S.D. $=0.38$ ). In particular, they perceived the course with visual communication in communicating content at high level $(\overline{\mathrm{x}}=4.47$, S.D. $=0.37)$, enhancing memory at very high level $(\overline{\mathrm{x}}=4.52$, S.D. $=0.47)$, and increasing learning at very high level $(\overline{\mathrm{X}}=4.69$, S.D. $=0.40)$. Students thought that the course with visual communication drew their attention with graphics, colors, animations, videos, and typography better than texts while helping improve their memory retention and content comprehension. They also felt that they learnt better with visual communication when they used it to recall, retain, and retrieve the course content.

\subsection{Effects of Visual Communication on Memory Enhancement}

Students were given the pre-test before starting the course and post-test at the end of the course. A memory test was used to examine the effects of visual communication on memory enhancement before and after the implementation of visual communication. 3 experts verified the validity of the memory test with the index of item-objective congruence (IOC) with values more than 0.60 and the memory test was pilot tested with a group of 10 non-targeted samples with the value of reliability coefficient at 0.83 . T-test for dependent samples was then used to compare the means between pre-test and post-test results and to examine whether there was a statistical difference between the means of two tests before and after implementing visual communication. Table 3 illustrated memory enhancement of students in the pre-test and post-test results. 
Table 3. Memory Enhancement before and after Implementing Visual Communication

\begin{tabular}{llllll}
\hline Student Memory & Total Scores & $\overline{\mathrm{X}}$ & S.D. & $\mathrm{t}$-test & Sig* $^{*}$ \\
\hline Pre-test & 20 & 15.05 & 1.43 & $11.49^{*}$ & 0.00 \\
Post-test & 20 & 19.47 & 1.17 & & \\
\hline
\end{tabular}

From Table 3, the pre-test scores were 15.05 (S.D. = 1.43). After the implementation of visual communication, the post-test scores increased to 19.47 (S.D. $=1.17$ ). They were much higher than pre-test scores at statistical significance of .05 level. It meant that students had better memorization when using visual communication to generate appeal, comprehension and retention in the course, which led to memory enhancement and better learning performance.

The main findings indicated that the use of visual communication in the course was effective according to students' perceived effectiveness and increased memory enhancement, which led to better learning performance. The findings were in line with Levie \& Lentz (1982) who reviewed 55 studies on the effects of text illustration as compared to text alone and found that they increased understanding in 98 percent of the experiments because pictures facilitate learning by providing clarifying examples, extra-lingual information, contexts for interpretation, and redundancy which aids recall. Hewlett-Packard Development Company (2004) also supported that the more visual content in a presentation, the more memorable the information will be over the long term and plenty of evidence from formal research studies indicated that communication that has a visual component can be far more effective than communication that does not. Therefore, incorporating visual elements into texts provided positive results in memory enhancement, which was in accordance with Vanichvasin (2013) who found that most students could recall content when incorporating visual elements such as infographics into the course content while Udomon et al. (2013) found that visual stimulation is more effective than audio stimuli at achieving higher memory retention and recall (with a p-value $<.05$ ). The findings can help instructors gain awareness of the relationship between visual communication and memory enhancement so that they can better integrate visual communication to help enhance memory of students and create better learning performance in the future. Therefore, using visual communication seemed necessary and found effective in enhancing student memory, as the research findings illustrated that there was significant difference in scores before and after the implementation of visual communication. The current study can provide better understanding of why visual communication can enrich communication in terms of activating attention, generating understanding and maintaining retention while providing guidelines of how to use visual communication as a useful teaching and learning tool in an educational context to enhance student memory and increase better learning performance.

\section{Conclusion and Recommendation}

In conclusion, visual communication produced positive results. It can be applied in courses in educational context to communicate course content more effectively with graphics, colors, animations, videos, typography or any other forms of visuals for better attention, comprehension and retention, enhance memory by helping students recall, retain, and retrieve course content, and motivate learning with interest and satisfaction for better memorization and learning performance. However, memory testing can be carried out again to confirm the findings as time may affect student memory. Also, the research on visual communication has been done in the communication skills course, which was not complex discipline. The next research may be conducted in other courses with more complex disciplines to confirm the findings and explore the differences in disciplines if any.

\section{References}

Alfi, C. F. (2011). Visual communication. Retrieved from http://www.slideshare.net/cokyfauzialfi/visual-communication-10044491?from_search=2

Avneet, G., Pal Singh, M., \& Siddhraj, S. (2018). A review on learning and memory. Journal of Drug Delivery and Therapeutics, 8(2), 153-157. https://doi.org/10.22270/jddt.v8i2.1671

Basker, K. (2009). Visual communication. Retrieved from http://www.slideshare.net/basssk/visual-communication-2028375

Clark, R. C., \& Mayer, R. E. (2011). E-learning and the science of instruction ( $3^{\text {rd }}$ ed.). Hoboken, N.J.: Pfeiffer. https://doi.org/10.1002/9781118255971

Choudhary, A. (2019). How is visual communication different from graphic design?. Retrieved from https://www.lcca.org.uk/blog/careers/how-is-visual-communication-different-from-graphic-design/

Dewan, P. (2015). Words versus pictures: Leveraging the research on visual communication. Partnership: The 
Canadian Journal of Library and Information Practice and Research, 10(1), 1-10. https://doi.org/10.21083/partnership.v10i1.3137

Digital, S. M. (2014). Visual communication tip: Memory recall improves when visuals are used. Retrieved from https://digitalsplashmedia.com/2014/04/visual-communication-tip-memory-recall-improves-when-visuals-a re-used/

Dimension, D. (2013). Visual communications: A visual solution for everyone. Retrieved from http://www.dimensiondata.com/Global/Technologies/Visual-Communications

Eisenberg, H. (2014). Humans process visual data better. Retrieved from http://www.t-sciences.com/news/humans-process-visual-data-better

Few, S. (2006). Visual communication. Retrieved from www.perceptualedge.com/.../Visual_Communication.pdf

Freeman, J. (2019). Benefits of visual communication. Retrieved from https://www.edrawsoft.com/benefits-of-visual-communication.html

Gutierrez, K. (2014). Studies confirm the power of visuals in elearning. Retrieved from https://www.shiftelearning.com/blog/bid/350326/studies-confirm-the-power-of-visuals-in-elearning

Hewlett-Packard Development Company. (2004). The power of visual communication. Retrieved from http://hp.com/large/.../power-of-visual-communication.pdf

Jantanamsri, T. (2017). Content and forms of communication via infographic to perception and memory on infographic Thailand facebook fanpages. (Master's Thesis). Master of Communication Arts (Strategic Communication). Graduate School. Bangkok University.

Khadimally, S. (2016). Visual communications and learning. US-China Education Review A, 6(8), 466-479. https://doi.org/10.17265/2161-623X/2016.08.002

Kosslyn, S. M. (2007). Clear and to the point: 8 psychological principles for compelling powerPoint presentations. Oxford: Oxford UP.

Kouyoumdjian, H. (2012). Learning through visuals. Retrieved from https://www.psychologytoday.com/us/blog/get-psyched/201207/learning-through-visuals

Lankow, J., Ritchie, J., \& Crooks, R. (2012). Infographics: The power of visual storytelling. John Wiley \& Sons.

Levie, W. H., \& Lentz, R. (1982). Effects of text illustrations: A review of the research. Educational Communication and Technology: A Journal of Theory, Research, and Development, 30(4), 195-232.

Mala, D. (2017). Thai students still lag the rest. Retrieved from https://www.bangkokpost.com/learning/news/1228212/thai-students-still-lag-the-rest

Mayer, R. E. (2003). Learning and instruction. Upper Saddle River, N.J.: Merrill Prentice Hall.

Mayhew, R. (2017). Why is it important for teachers to have good communication skills?. Retrieved from https://bizfluent.com/info-11404496-important-teachers-good-communication-skills.html

Movien, R. (2015). A retrospective on constructing a personal narrative on agile development. The 10th International Conference on Knowledge, Information and Creativity Support System (KICSS2015). Phuket, Thailand.

Nelson, D. L., Reed, U. S., \& Walling, J. R. (1976). Pictorial superiority effect. Journal of Experimental Psychology: Human Learning \& Memory, 2, 523-528. https://doi.org/10.1037/0278-7393.2.5.523

Paivio, A. (1986). Mental representations: A dual coding approach. New York: Oxford UP.

Pan Y. (2012). Attentional capture by working memory contents. Canadian Journal of Experimental Psychology, 64(2), 124-128. https://doi.org/10.1037/a0019109

Rasi, P. (2016). The development of infographic media in an introduction to computer network course for the third-year vocational students (Master's Thesis). Educational Technology and Communications. Rajamangala University of Technology Thanyaburi.

Reiser, R. A., \& Dempsey, J. V. (2007). Trends and issues in instructional design and technology (4th ed.). Columbus, O.H.: Pearson.

Saengboon, S. (2002). Beliefs of Thai teachers about communicative language teaching. (Unpublished doctoral dissertation), Indiana University. 
Saengboon, S. (2006). CLT revisited. NIDA Language and Communication Journal, 11(11), 136-148.

Sanitchai, P., \& Darrin, T. (2018). The relationship of active learning and academic achievement among provincial university students in Thailand. APHEIT International Journal, 7, 47-61.

Sharma, A., Bhosle, A., \& Chaudhary, B. (2012). Consumer perception and attitude towards the visual elements in social campaign advertisement. IOSR Journal of Business and Management (IOSRJBM), 3(1), 6-17. https://doi.org/10.9790/487X-0310617

Sless, D. (1981). Learning and visual communication. New York-Toronto: Croom Helm London John Wiley \& Sons.

Smiciklas, M. (2012). The power of infographics: Using pictures to communicate and connect you're your audience. Indiana: QUE Publishing.

Smilek, D., Dixon, M. J., Cudahy, C., \& Merikle, P. M. (2002). Research report: Synesthetic color experiences influence memory. Psychological Science, 13(6), 548-552. https://doi.org/10.1111/1467-9280.00496

Smith, K. (2005). Handbook of visual communication: Theory, methods, and media. New Jersey: Lawrence Erlbaum Associates, Inc.

Stokes, S. S. (2002). Visual literacy in teaching and learning: A literature perspective. Electronic Journal for the Integration of Technology in Education, 7(1, Spring), 10-19.

Thamraksa, C. (2003). Student-centered learning: Demystifying the myth. Studies in language and language teaching, 12, 59-70.

Van De Ven, A. H., \& Johnson, P. E. (2006). Knowledge for theory and practice. Academy of Management Review, 31(4), 802-821. https://doi.org/10.2307/20159252

Vanichvasin, P. (2013). Enhancing the quality of learning through the use of infographics as visual communication tool and learning tool. Proceedings of ICQA 2013: The International Conference on QA Culture: Cooperation or Competition. Bangkok, Thailand. p. 135-142.

Wilmot Li, A. L., \& Berthouzoz, F. (2011). Design principles for visual communication. Communications of the ACM, 54(4), 60-69. https://doi.org/10.1145/1924421.1924439

Wulandari, T. A. (2018). A business guide to visual communication. Retrieved from https://visage.co/wp-content/uploads/2014/07/Business_Guide_to_Visual_Communication_by_Visage.pdf

Udomon, I., Xiong, C., Berns, R., Best, K., \& Vike, N. (2013). Visual, audio, and kinesthetic effects on memory retention and recall. Retrieved from http://jass.neuro.wisc.edu/2013/01/Group\%203.Udomon.Final\%20Submission.pdf

\section{Copyrights}

Copyright for this article is retained by the author(s), with first publication rights granted to the journal.

This is an open-access article distributed under the terms and conditions of the Creative Commons Attribution license (http://creativecommons.org/licenses/by/4.0/). 